\title{
Optical Coherence Tomography Findings in Anterior Chamber Ointment Globule after Phacoemulsification
}

\author{
Ahmad M. Mansour ${ }^{a, b}$ Randa S. Haddad ${ }^{a}$ Haytham I. Salti ${ }^{a}$ \\ Zuhair Habbal ${ }^{c}$ \\ ${ }^{a}$ Department of Ophthalmology, American University of Beirut, ${ }^{b}$ Department of \\ Ophthalmology, Rafic Hariri University Hospital, and ${ }^{\mathrm{C}}$ Department of Pathology and \\ Laboratory Medicine, American University of Beirut, Beirut, Lebanon
}

\section{Key Words}

Optical coherence tomography · Anterior chamber ointment globule · Phacoemulsification

\begin{abstract}
We present 2 cases of anterior chamber ointment with evidence of progressive endothelial cell loss. In both cases, an anterior segment optical coherence tomography (OCT) was similar to an OCT of a tobramycin-dexamethasone ointment placed on a pen tip. An anterior segment OCT also demonstrated the direct contact of the globule with the corneal endothelium. A gas chromatography/mass spectrometry analysis documented the similarity to tobramycindexamethasone ointment in 1 case. Anterior segment OCT can help in confirming the diagnosis. Corneal endothelial injury is a continuous process, and its clinical manifestation is related to the size of the globule, the initial endothelium count, and the duration of ointment contact, which is related to supine positioning. It is advisable to avoid ointments in the immediate postoperative period, especially in corneal wounds larger than $3 \mathrm{~mm}$.
\end{abstract}

(C) 2015 The Author(s)

Published by S. Karger AG, Basel

\section{Introduction}

Retained cilia, metallic fragments, and ointments (chloramphenicol or tobramycindexamethasone) are rare occurrences in phacoemulsification today [1-13]. Ophthalmic 
Mansour et al.: Optical Coherence Tomography Findings in Anterior Chamber Ointment Globule after Phacoemulsification

ointments are typically prepared in white petrolatum, parahydrobenzoic acids (parabens), mineral oils, or in a combination of these. Recent surveys showed that ointments are still commonly used after phacoemulsification [14], probably because they decrease the postoperative discomfort [15]. The decision to remove an ointment globule surgically is controversial and must be based on the individual clinical examination. While on the one hand, a larger part of the literature has confirmed the benign nature of ointments [3], other reports have pointed out ocular hazards [2]. We present optical coherence tomography (OCT) findings of constant corneal touch and evidence of endothelial loss in the eye with the globule. Based on our observations and on the literature [16-18], ointments may cause definite endothelial loss, and this is related to the size of the ointment, the duration of contact, the head position, and ocular movement as well as to the baseline endothelial count.

\section{Case Reports}

Case 1

A 84-year-old patient presented with foreign-body sensation and vision loss in the right eye 3 weeks after uneventful sutureless corneal phacoemulsification with implant in the right eye. The patient reported vision loss while lying in the supine position. The medical history was positive for rheumatoid arthritis, Sjögren's syndrome, and paraproteinemia (lambda gammopathy). The patient was extremely short and very difficult to be placed in front of the slit lamp. Best-corrected visual acuity was 20/200 (6/60). An anterior chamber cyst was detected (fig. 1). OCT revealed marked cystoid macular edema with a central macular thickness of $586 \mu \mathrm{m}$ (fig. 2). Our differential diagnosis was paraproteinemic maculopathy versus cystoid macular edema secondary to ointment-induced intraocular inflammation. Topical ketorolac tromethamine was applied, and visual acuity recovered to 20/30 (6/9) with flattening of the fovea and a central macular thickness of $280 \mu \mathrm{m}$. The endothelial count was decreased compared to the fellow eye (which had had a similar cataract operation by the same surgeon; 971 vs. 1,344 cells $/ \mathrm{mm}^{2}$ ), denoting possible damage from the globule, and hence the patient did consent to its removal. Anterior segment OCT (fig. 3) revealed a pattern similar to a tobramycin-dexamethasone ointment placed on a pen tip (fig. 4): a homogeneous hyperreflective mass. Besides, direct globule-endothelial touch was documented by OCT.

The globule was removed passively by placing an anterior chamber maintainer under low flow and with very minimal aspiration on an aspiration system connected to a lens cartridge (fig. 5). When the globule was inside the cartridge shaft, the infusion was removed. The surgical specimen was sent for gas chromatography/mass spectrometry analysis, which showed several dominant peaks consistent with docosane, tricosane, and tetracosane hydrocarbons. Samples of a tobramycin-dexamethasone ointment (TobraDex; Alcon Laboratories, Fort Worth, Tex., USA) in a petrolatum and lanolin base were also sent for gas chromatography/mass spectrometry analysis. The ointment peaks coincided with those of the surgical specimen, confirming that the intracameral globule was a remnant of the ophthalmic ointment. The postoperative course was smooth with preservation of vision.

Case 2

This 82-year-old woman had an uneventful sutureless corneal phacoemulsification with implant in the right eye by the same surgeon as case 1 . Postoperative visual acuity was $20 / 50(6 / 15)$ with an intraocular pressure of $14 \mathrm{~mm} \mathrm{Hg}$, and the surgeon noted a globule superiorly. Vision stabilized at the 20/40 (6/12) level till 18 months after surgery, when 
Mansour et al.: Optical Coherence Tomography Findings in Anterior Chamber Ointment Globule after Phacoemulsification

vision dropped to $20 / 80(6 / 24)$ with corneal edema and to finger counting 1 month later. Since then, the patient suffered from recurrent episodes of epithelial defects (fig. 6). An anterior segment OCT of the globule was similar to that of case 1 (fig. 7). Also, the anterior segment OCT demonstrated direct contact of the globule with the corneal endothelium. Thirty months after surgery, the patient agreed to have the ointment removed with application of an amniotic membrane. The same technique was applied as in case 1, except that some ointment was left behind and was aspirated with a Simcoe irrigation aspiration system. Postoperative vision was finger counting at $2 \mathrm{~m}$. Specular microscopy of the central cornea of the fellow eye revealed a low endothelial count $\left(621\right.$ cells $\left./ \mathrm{mm}^{2}\right)$.

\section{Discussion}

Scheie et al. [17] evaluated the effects of ointments by injecting common ophthalmic ointment bases in the anterior chamber of rabbit eyes. The major predictor of reaction severity was the volume of ointment instilled. A volume of $0.01 \mathrm{ml}$ had little effect on the eye, regardless of the type of ointment. A volume of $0.1 \mathrm{ml}$ produced an overwhelming reaction in most eyes with prompt glaucoma [17]. After injection of petrolatum, there was an upward migration of the globule with localized corneal edema superiorly in $43 \%$ of the eyes by 2 weeks and in all eyes by 14 weeks. Histopathologically, the endothelium was absent in the region of the cornea in contact with the petrolatum [17]. In a survey by Fraunfelder and Hanna [18], 50 of 95 cases of intraocular ointment showed no apparent side effects [6]. Thus, it has been suggested that a small amount of ointment may be watched until signs of toxicity develop [8]. Scheie et al. [17] reported 2 patients, one of whom was observed for 18 years with retained miotic ointment (peanut oil-based diisopropyl fluorophosphate). Humayun et al. [3] described 4 cases with ointment spherules with a follow-up ranging from 13 to 46 months after lens extraction, none of which were associated with complications.

Predisposing factors to ingress of ointment into the anterior chamber include a short nonoblique uniplanar wound [19], negative pressure on removal of the lid speculum [5], manipulating the paracentesis or phacoemulsification wound with a forceps, or enlarging the incision if the plane of the second incision is different from that of the first [3].

Anterior chamber ophthalmic ointment retaining has been noted in cataract surgeries $[17,18]$, radial keratotomy [20], and recently after sutureless phacoemulsification [1-16]. It is a rare condition most often missed by the operating surgeon (especially in eyes with ptosis) or mistaken for other entities including lens remnant, epithelial inclusion cyst, tumors arising from the iris or ciliary body, parasitic infestation, and silicone oil droplets. It can present as a spherical droplet of ointment adherent to the intraocular lens or as a free-floating globule that moves with head movements. Transient obscurations of vision have been noted in some patients [16]. Complications have included corneal decompensation [16], secondary glaucoma $[9,20]$, uveitis $[10,20]$, toxic anterior segment syndrome [1, 2], and cystoid macular edema. More severe complications occurred when oily material was observed as a filmlike coating of the corneal endothelium requiring either penetrating keratoplasty or Descemet's stripping endothelial keratoplasty $[2,8]$. When there is adherence to the intraocular lens, intraocular exchange is performed $[2,12]$. The first patient had decreased vision from cystoid macular edema, and the retinal specialist suspected paraproteinemic maculopathy [21] or ointment inflammation, and the macular edema resolved on antiinflammatory drops. The presence of the ointment probably resulted in some endothelial loss (comparing the 2 eyes, as we do not have preoperative endothelial counts), and the patient accepted removal of the ointment under topical anesthesia. Similarly, 2 cases had the 
Mansour et al:: Optical Coherence Tomography Findings in Anterior Chamber Ointment Globule after Phacoemulsification

same presenting sign in anterior segment ointment as in chronic cystoid macular edema [7, 13].

A 3.5-mm temporal clear corneal incision was made, and the globule was expressed passively by pressing on the posterior lip of the corneal wound [4]. According to Wong and Bank [5], the droplet was surgically explanted using a lens glide and an ophthalmic viscosurgical device through an enlarged clear corneal incision. We let the ointment globule pass via an infusion side port to the corneal incision through a cartridge attached to a suction syringe (fig. 5).

We demonstrated that our cases had ointment inside the eye by anterior segment OCT findings similar to an OCT of ointment placed on a pen tip as well as by gas chromatography/mass spectrometry. Anterior segment OCT demonstrated a homogenous wellcircumscribed hyperintense lesion in the superior anterior chamber, pressing on the anterior iris surface [4]. This is the second report of anterior segment OCT of ointment globules in the anterior chamber [4]. In conclusion, potential corneal endothelial damage (mild in case 1 and severe in case 2) from anterior chamber ointment was outlined in the literature as related to the volume of ointment, the state of the endothelium, and the duration of contact between the ointment and the endothelium (which is related to the activity of the patient and the supine position). Finally, it is advisable to avoid ointment in the immediate postoperative period, especially in phacoemulsification corneal wounds larger than $3 \mathrm{~mm}$.

\section{Statement of Ethics}

This study was done according to the Declaration of Helsinki after written patient consent.

\section{Disclosure Statement} tioned.

The authors have no financial or proprietary interest in any material or method men-

\section{References}

1 Mamalis N, Edelhauser HF, Dawson DG, Chew J, LeBoyer RM, Werner L: Toxic anterior segment syndrome. J Cataract Refract Surg 2006;32:324-333.

-2 Werner L, Sher JH, Taylor JR, Mamalis N, Nash WA, Csordas JE, Green G, Maziarz EP, Liu XM: Toxic anterior segment syndrome and possible association with ointment in the anterior chamber following cataract surgery. J Cataract Refract Surg 2006;32:227-235.

3 Humayun M, Gottlieb CC, Rafuse PE: Intraocular ophthalmic ointment following clear corneal phacoemulsification: clinical implications. J Cataract Refract Surg 2006;32:2135-2138.

-4 Wong VWY, Chu KO, Lam PTH, Yam GHF, Lai TYY: Late appearance of an intracameral ophthalmic ointment globule after uneventful phacoemulsification. Jpn J Ophthalmol 2009;53:553-555.

-5 Wong JG, Bank A: Surgical removal of intraocular antibiotic ointment after routine cataract phacoemulsification. J Cataract Refract Surg 2006;32:890-892.

6 Sbordone S, Savastano A, Romano V: Ointment in the anterior chamber. JAMA Ophthalmol 2014;132:1425.

-7 Shukla AN, Daly MK, McKnight CJ, Freddo T: Intraocular ophthalmic ointment following anterior segment surgery. J Cataract Refract Surg 2011;37:2218-2221.

-8 Chen KH, Lin SY, Li MJ, Cheng WT: Retained antibiotic ophthalmic ointment on an intraocular lens 34 months after sutureless cataract surgery. Am J Ophthalmol 2005;139:743-745. 
Case Reports in

Ophthalmology

\begin{tabular}{l|l}
\hline Case Rep Ophthalmol 2015;6:469-476 \\
\hline DOI: 10.1159/000442970 & $\begin{array}{l}\text { ○ 2015 The Author(s). Published by S. Karger AG, Basel } \\
\text { www.karger.com/cop }\end{array}$ \\
\hline
\end{tabular}

Mansour et al.: Optical Coherence Tomography Findings in Anterior Chamber Ointment Globule after Phacoemulsification

9 Riedl M, Maca S, Amon M, Nennadal T, Kruger A, Barisani T: Intraocular ointment after small-incision cataract surgery causing chronic uveitis and secondary glaucoma. J Cataract Refract Surg 2003;29:10221025.

10 Ugurbas SC, Akova YA: Toxic anterior segment syndrome presenting as isolated cystoid macular edema after removal of entrapped ophthalmic ointment. Cutan Ocul Toxicol 2010;29:221-223.

11 Aralikatti AKV, Needham AD, Lee MW, Prasad S: Entry of antibiotic ointment into the anterior chamber after uneventful phacoemulsification. J Cataract Refract Surg 2003;29:595-597.

$\$ 12$ Chew JJL, Werner L, Mackman G, Mamalis N: Late opacification of a silicone intraocular lens caused by ophthalmic ointment. J Cataract Refract Surg 2006;32:341-346.

13 Lee EJ, Wong R, Laidlaw DA: Late-onset cystoid macular edema associated with small-incision cataract surgery and inadvertent entry of chloramphenicol ointment into the anterior chamber. Ophthalmic Surg Lasers Imaging 2010;9:1-3.

14 Matsuura K, Mori T, Miyamoto T, Suto C, Saeki Y, Tanaka S, Kawamura H, Ohkubo S, Tanito M, Inoue Y: Survey of Japanese ophthalmic surgeons regarding perioperative disinfection and antibiotic prophylaxis in cataract surgery. Clin Ophthalmol 2014;29;8:2013-2018.

-15 Sipos E, Stifter E, Menapace R: Patient satisfaction and postoperative pain with different postoperative therapy regimens after standardized cataract surgery: a randomized intraindividual comparison. Int Ophthalmol 2011;31:453-460.

$\$ 16$ Wenger A, Hughes BM, Wiggins MN: An anterior chamber mass discovered after routine cataract surgery. Ophthalmic Surg Lasers Imaging 2005;36:503-505.

17 Scheie HG, Rubenstein RA, Katowitz JA: Ophthalmic ointment bases in the anterior chamber. Clinical and experimental observations. Arch Ophthalmol 1965;73:36-42.

18 Fraunfelder FT, Hanna C: Ophthalmic ointment. Trans Am Acad Ophthalmol Otolaryngol 1973;77:0P467OP475.

19 Taban M, Rao B, Reznik J, Zhang J, Chen Z, McDonnell PJ: Dynamic morphology of sutureless cataract wounds. Effect of incision angle and location. Surv Ophthalmol 2004;49(suppl 2):S62-S72.

20 Garzozi HJ, Muallem MS, Harris A: Recurrent anterior uveitis and glaucoma associated with inadvertent entry of ointment into the anterior chamber after radial keratotomy. J Cataract Refract Surg 1999;25:16851687.

21 Mansour AM, Arevalo JF, Badal J, Moorthy RS, Shah GK, Zegarra H, Pulido JS, Charbaji A, Amsel em L, Lavaque AJ, Casella A, Ahmad B, Paschall JG, Caimi A, Staurenghi G: Paraproteinemic maculopathy. Ophthalmology 2014;121:1925-1932.

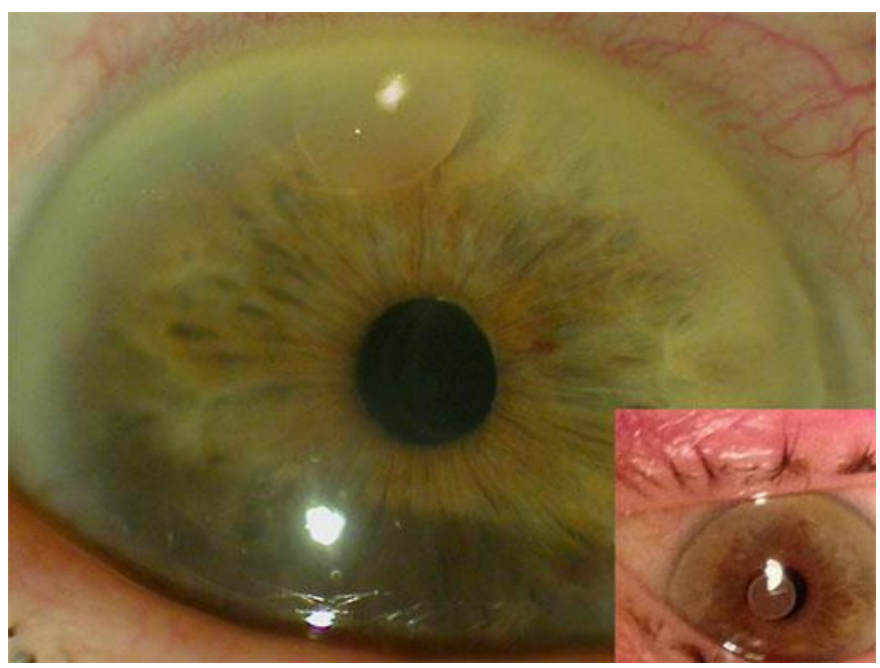

Fig. 1. Case 1. Superior globule in the right eye at $12 \mathrm{o}$ 'clock in the sitting position, while the inset is taken in the supine position with the globule abutting the central cornea. 


\section{Case Reports in \\ Ophthalmology}

\begin{tabular}{l|l}
\hline Case Rep Ophthalmol 2015;6:469-476 \\
\hline DOI: 10.1159/000442970 & $\begin{array}{l}\text { ○ 2015 The Author(s). Published by S. Karger AG, Basel } \\
\text { www.karger.com/cop }\end{array}$ \\
\hline
\end{tabular}

Mansour et al.: Optical Coherence Tomography Findings in Anterior Chamber Ointment Globule after Phacoemulsification

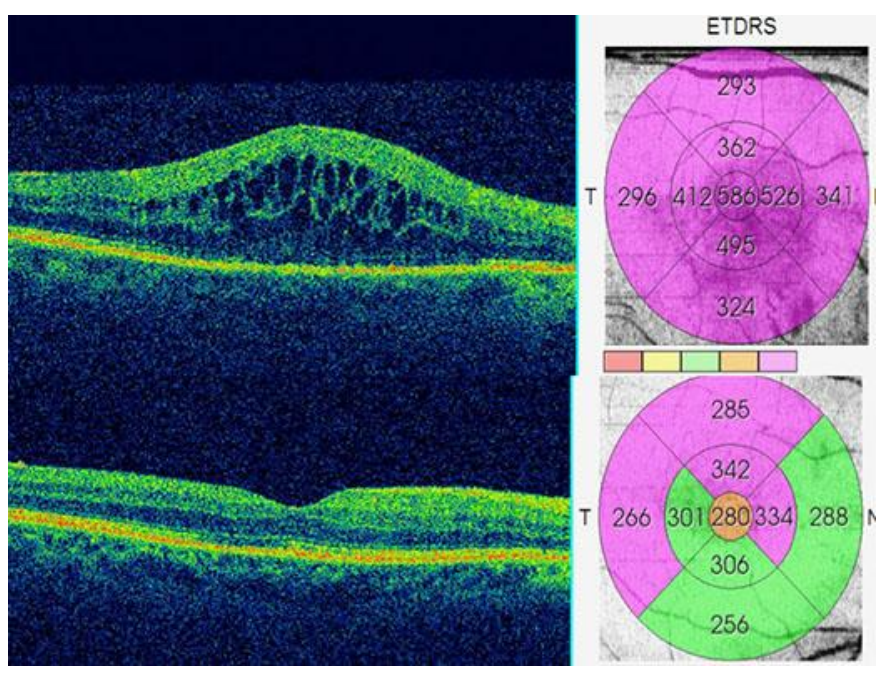

Fig. 2. Case 1. OCT of the macula shows marked cystoid macular edema in the right eye (top) and a normal contour in the left eye (bottom).

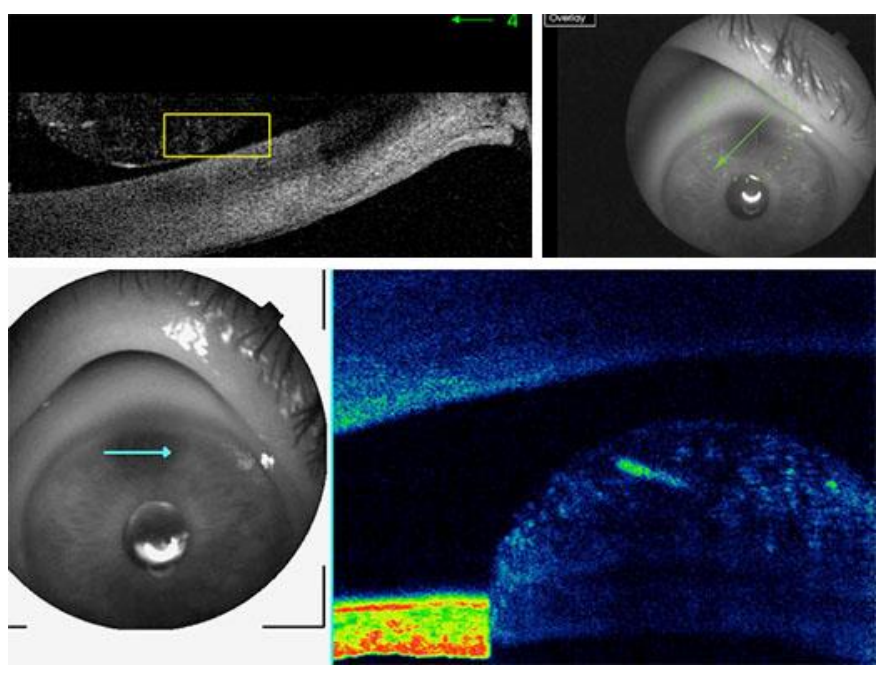

Fig. 3. Case 1. Anterior OCT scans of the right eye. Superior scan: oblique scan shows a homogeneous hyperreflective mass touching the endothelium. Inferior scan: horizontal scan in color mode. The globule shows diffuse hyperreflective foci (yellow dots) similar to the neighboring iris. 


\section{Case Reports in \\ Ophthalmology}

\begin{tabular}{l|l}
\hline Case Rep Ophthalmol 2015;6:469-476 \\
\hline DOI: 10.1159/000442970 & $\begin{array}{l}\text { ○ } 2015 \text { The Author(s). Published by S. Karger AG, Basel } \\
\text { www.karger.com/cop }\end{array}$ \\
\hline
\end{tabular}

Mansour et al.: Optical Coherence Tomography Findings in Anterior Chamber Ointment Globule after Phacoemulsification

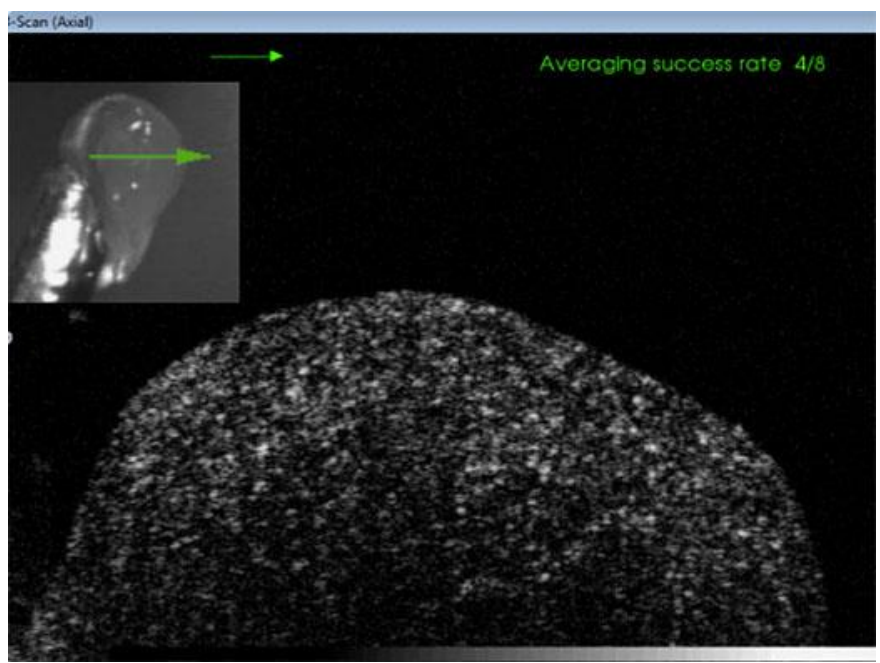

Fig. 4. OCT of tobramycin-dexamethasone ointment placed on a pen tip showing diffuse hyperreflective foci.

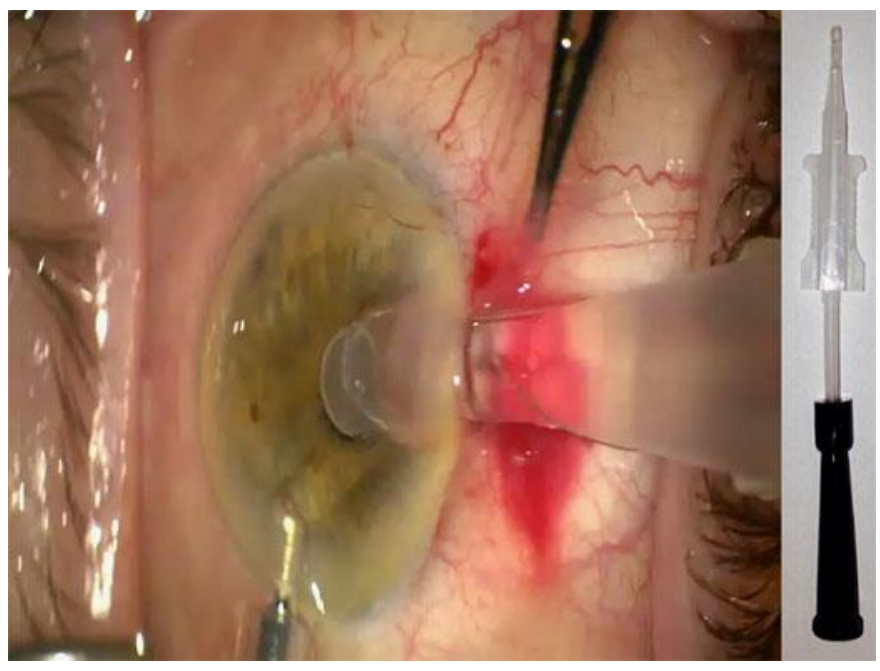

Fig. 5. Case 1. Operative technique: a slow-flow infusion cannula is placed temporally (left). A three-plane keratome limbal incision at 12 o'clock is followed by insertion of an intraocular cartridge attached to a catheter (right) connected to a syringe to allow minimal suction. 


\section{Case Reports in \\ Ophthalmology}

\begin{tabular}{l|l}
\hline Case Rep Ophthalmol 2015;6:469-476 \\
\hline DOI: $10.1159 / 000442970$ & $\begin{array}{l}\text { (c) 2015 The Author(s). Published by S. Karger AG, Basel } \\
\text { www.karger.com/cop }\end{array}$
\end{tabular}

Mansour et al.: Optical Coherence Tomography Findings in Anterior Chamber Ointment Globule after Phacoemulsification

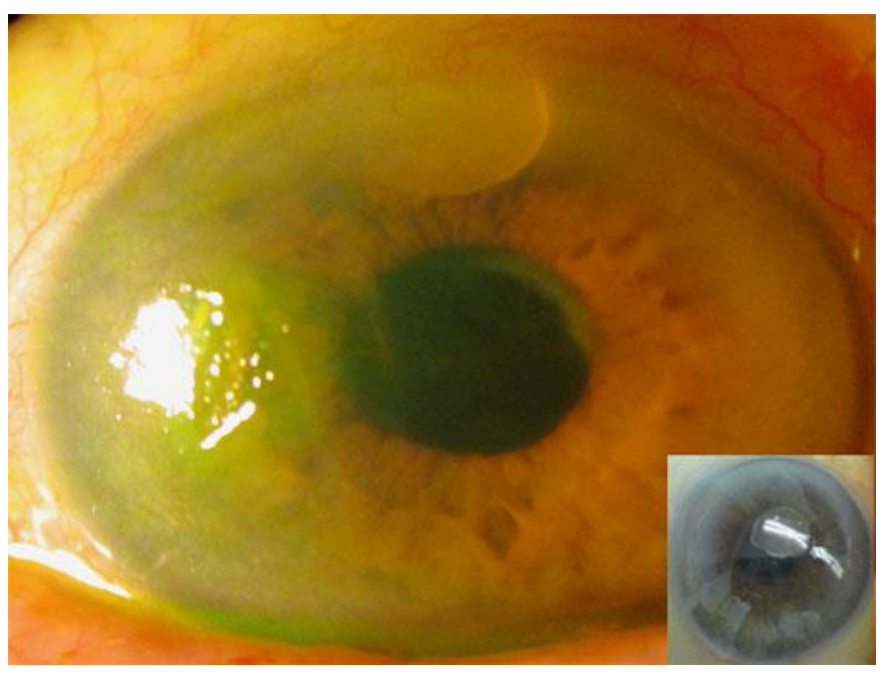

Fig. 6. Case 2. A superior globule is present in the anterior chamber superiorly, while the recurrent erosion is noted temporally. There is a diffuse corneal haze from corneal decompensation secondary to the globule contacting the central cornea in the supine position (lower right inset).
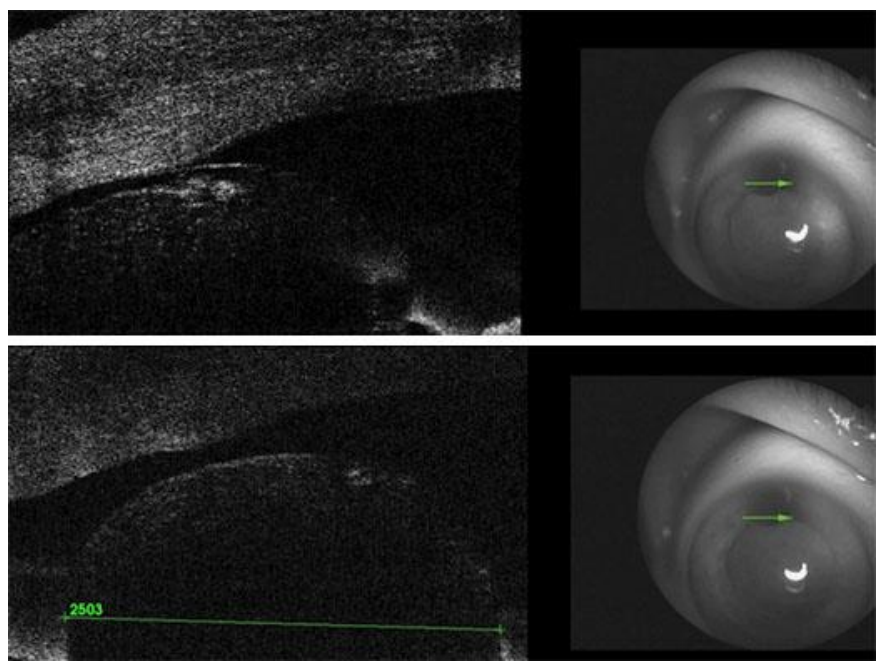

Fig. 7. Case 2. Anterior horizontal OCT scans of the right eye. The upper scan shows direct contact between the hyperreflective globule and the corneal endothelium. The lower scan delineates the size of the globule to allow planning of the limbal incision size. 